Author has nothing to disclose with regard to commercial support.

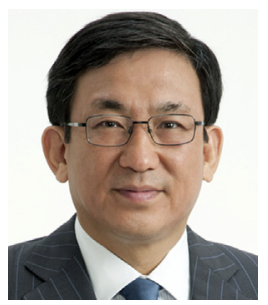

\section{PROPOSAL FOR \\ BUILDING AN \\ INFRASTRUCTURE FOR \\ INTERNATIONAL \\ RANDOMIZED, CONTROL \\ TRIALS AND A \\ COMPREHENSIVE REGISTRY OF INFECTIVE}

\section{ENDOCARDITIS}

\section{To the Editor:}

In this issue of the Journal, Nappi and Spadaccio ${ }^{1}$ have once again addressed their concern about the use of conventional prostheses for active infective endocarditis (IE) associated with substantial annular and periannular destruction. On the basis of their extensive experience with allografts, they strongly argue for the merits of allografts, which include their relative resistance to infection and the ease with which they can be applied to severely infected aortic roots.

In their provocative letter, Nappi and Spadaccio ${ }^{1}$ posed 2 challenging questions: (1) "Can we stitch in an infected annulus?" and (2) "Should we rethink the current guidelines for IE?" To answer their first question, I must say that in general, all surgeons agree that radical débridement (complete removal of foreign material, necrotic tissue, vegetation, and biofilm) is essential to avoid recurrent infection. ${ }^{2}$ The question remains, however, how to avoid overlooking pockets of infection and expose entirely healthy, well-vascularized tissue, because vegetations and necrotic tissue may harbor or hide viable organisms. ${ }^{2}$ Then next challenging issue is how to reconstruct the annulus or left ventricular outflow tract after radical débridement. For that purpose, most surgeons prefer to perform aortic root reconstruction with an allograft rather than conventional prosthetic valve implantation, combining annular reconstruction

\footnotetext{
The Editor welcomes submissions for possible publication in the Letters to the Editor section that consist of commentary on an article published in the Journal or other relevant issues. Authors should: • Include no more than 500 words of text, three authors, and five references. • Type with double-spacing. • See http://jtcs.ctsnetjournals.org/ misc/ifora.shtml for detailed submission instructions. • Submit the letter electronically via jtcvs.editorialmanager.com. Letters commenting on an article published in the JTCVS will be considered if they are received within 6 weeks of the time the article was published. Authors of the article being commented on will be given an opportunity of offer a timely response ( 2 weeks) to the letter. Authors of letters will be notified that the letter has been received. Unpublished letters cannot be returned.
}

with bovine or autologous pericardium, because intermediate survival and cure of infection are the primary issues in this context. In this regard, this simplest solution may be the cleverest. In the long term, however, the issue of durability of allografts versus conventional bioprostheses still remains. $^{3}$

To answer their second question- "Should we rethink the current guidelines for IE?"-Nappi and Spadaccio ${ }^{1}$ challenged the Society of Thoracic Surgeons' 2011 guidelines, ${ }^{4}$ which state the following: "When periannular abscess is associated with IE, it is reasonable to use a mechanical or stented tissue valve if radical débridement is carried out and the valve can be anchored to healthy and strong tissue." The most recent 2016 American Association for Thoracic Surgery (AATS) guidelines ${ }^{2}$ contain the following recommendation: "For invasive and destructive native aortic valve IE requiring root reconstruction and replacement, using an allograft may be beneficial, but a prosthetic bioroot or prosthetic valved conduit with a mechanical or bioprosthetic valve are acceptable alternatives, with choice guided by surgeon training and experience." I wish to remind Nappi and Spadaccio that allografts are not easily obtained in most developing countries in Africa, in the Middle East, and even in Japan, China, India, and most of Southeast Asia. Surgeons in these countries have to manage by themselves to reconstruct aortic valves damaged by invasive and destructive IE without the use of allografts. For prosthetic aortic valve IE, the updated AATS guidelines ${ }^{2}$ recommend the following: "If there is annulus destruction and invasion outside the aortic root and root reconstruction and replacement is required, an allograft or a biologic tissue root is preferable to a prosthetic valved conduit." For surgeons who have ready access to allografts, allograft root replacement may be the procedure of choice; for surgeons whose access to allografts is limited, however, extensive débridement of the destroyed annulus, followed by biological tissue root reconstruction with or without support of autologous or bovine pericardium, may be the only option.

Thanks to the leadership of both the AATS and the Society of Thoracic Surgeons, the guidelines for IE have been updated. ${ }^{2,4}$ The issue is how we can increase the class I or IIa recommendations with a higher level of evidence. I believe that this problem will be solved by only an international cooperative effort that includes the AATS, the Society of Thoracic Surgeons, the European Association for Cardio-Thoracic Surgery, and the Asian Society for Cardiovascular and Thoracic Surgery, all working together to build an infrastructure for international randomized, controlled trials ${ }^{5}$ and to establish a 
solid registry with a detailed database. Level A evidence can only be achieved by multiple randomized, controlled trials corroborated by high-quality registry studies. ${ }^{6}$ For these international leadership bodies, it is time to work on building the infrastructure for randomized, controlled trials and an IE registry to go beyond the existing guidelines.

Ko Bando, $M D, P h D$

Department of Cardiac Surgery The Jikei University School of Medicine

Tokyo, Japan

\section{References}

1. Nappi F, Spadaccio C. Simplest solutions are not always the cleverest. Can we stitch in an infected annulus? Should we rethink the current guidelines? J Thorac Cardiovasc Surg. 2017;154:1899-900.

2. Petterson GB, Coselli JS, Hussain ST, Griffin B, Blackstone EH, Gordon SM, et al. AATS Surgical Treatment of Infective Endocarditis Consensus Guidelines Writing Committee. 2016 The American Association for Thoracic Surgery (AATS) consensus guidelines: surgical treatment of infective endocarditis: executive summary. J Thorac Cardiovasc Surg. 2017;153: 1241-58.e29.

3. Kaya A, Schepens MA, Morshuis WJ, Heijmen RH, Brutel De La Riviere A, Dossche KM. Valve-related events after aortic root replacement with cryopreserved aortic homografts. Ann Thorac Surg. 2005;79:1491-5.

4. Byrne JG, Rezai K, Sanchez JA, Bernstein RA, Okum E, Leacche M, et al. Surgical management of endocarditis: The Society of Thoracic Surgeons clinical practice guideline. Ann Thorac Surg. 2011;91:2012-9.

5. Gardner TJ, Miller MA, O'Gara PT, Gelijns AC. Building an infrastructure for clinical trials in cardiac surgery. J Thorac Cardiovasc Surg. 2011;142: 265-6.

6. Svensson LG, Gillinov AM, Weisel RD, Keshavjee S, Bacha EA, Moon MR, et al. The American Association for Thoracic Surgery consensus guidelines: reasons and purpose. J Thorac Cardiovasc Surg. 2016;151:935-9.e1.

http://dx.doi.org/10.1016/j.jtcvs.2017.08.017

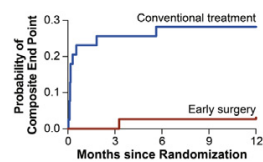

RANDOMIZED CLINICAL TRIALS OF SURGERY FOR INFECTIVE ENDOCARDITIS: REALITY VERSUS EXPECTATIONS!

Supplemental material is available online.

\section{Reply to the Editor:}

Lack of randomized clinical trials (RCTs) to provide level A evidence is particularly evident in guidelines for infective endocarditis (IE). ${ }^{1, \mathrm{E} 1-\mathrm{E} 5}$ Although it is fashionable to dismiss information, inferences, and comparisons of outcomes derived from observational experiences, much of the information used to manage patients with cardiac disease is derived from nonrandomized studies. ${ }^{2}$ It is sobering to know that only
$11 \%$ of American College of Cardiology/American Heart Association guidelines are based on level A evidence.

To date, only 1 RCT has been published for IE. ${ }^{\mathrm{E} 6}$ It included 76 patients in 2 centers during a 4.5 -year enrollment period to answer a specific question about the timing of surgical intervention for left-sided IE with large vegetations and important valve regurgitation: Should surgery be performed within 48 hours, or should one wait until heart failure symptoms occur? The attention paid to and the effect of this small study underscore the value of RCTs for evidence-based medicine.

Managing patients with IE involves a multispecialty team, and IE operations are difficult, with the highest reported mortality of any valve surgery. ${ }^{\mathrm{E} 1}$ Establishing an international registry and conducting an RCT, as proposed by Bando, ${ }^{1}$ would be ideal, but there are still limitations and pitfalls. ${ }^{2,4,5}$ Current outcomes are variable, and not every surgeon or center can be included, because experience with and mastery of the technical aspects of these operations are essential. This must be recognized so that appropriate referrals are made to centers of excellence. ${ }^{\mathrm{E}}$ Even then, there would remain many impediments to clinical trials of IE. Because IE operations are uncommon even at centers of excellence, low enrollment and underpowered studies would be a challenge. ${ }^{2,4,5}$ Equipoise is also challenging: The better the surgical judgment and experience, the more likely that equipoise will be lacking. ${ }^{2,4,5}$

The challenges in organizing an international registry are apparent when one considers the experience of ICE-PCS (International Collaboration on Endocarditis Prospective Cohort Study group), a multicenter international (64 sites from 28 countries) registry of patients with IE. ${ }^{\mathrm{E}}$ ICEPCS recently published results of early surgery for Staphylococcus aureus prosthetic valve IE. ${ }^{\mathrm{E}}$ During a 6-year period, only 168 patients who qualified for the study were enrolled, and in-hospital and 1-year mortalities were high, probably because of the wide variability in expertise among contributing centers. The CTSN (Cardiothoracic Surgery Clinical Trials Network) includes only select surgical programs and highly experienced operators. ${ }^{4}$ Despite the efforts of the CTSN to control site-to-site variability in technique, however, the surgical procedures are subject to modifications. Both technical expertise and procedural variation affect the actual treatment delivered in ways that may not be apparent. ${ }^{2,4}$

Ultimately, the primary goal is to improve patient outcomes, and it is imperative that there is transparency in reporting outcomes of IE operations by all centers. Clinical trials may serve to identify and disseminate more effective therapies. Because of the complexity, variability, and high-risk nature of IE surgery, trials must be designed with very specific questions and must ensure a standardized team approach to patient selection, 